Territorios 33 / Bogotá, 2015, pp. 33-61

ISSN: 0123-8418

ISSNe: 2215-7484

Procesos de ocupación del territorio, historia urbana y patrimonio II

\title{
Producción social, proceso participativo e intervención sostenible en el espacio público de los centros históricos. El caso de Pamplona, Colombia
}

Social Production, Participative Process and Sustainable

Intervention in the Public Space of Historical Centers. The Case of Pamplona, Colombia

Produção social, processo participativo e intervenção sustentável no espaço público de centros históricos. O caso de Pamplona, Colômbia

\section{Huber Giraldo Giraldo*}

Recibido: 15 de septiembre de 2014

Aceptado: 24 de abril de 2015

Doi: dx.doi.org/10.12804/territ33.2015.02

Para citar este artículo:

Giraldo G., H. (2015). Producción social, proceso participativo e intervención sostenible en el espacio público de los centros históricos. El caso de Pamplona, Colombia. Territorios, 33, 33-61. Doi: dx.doi.org/10.12804/ territ33.2015.02

* Arquitecto egresado de la Universidad del Valle, Cali, Valle del Cauca. Magister en Gestión Urbana, egresado de la Universidad Piloto de Colombia, Distrito Capital. Doctorando en Desarrollo Urbano Sustentable de la Universidad Politécnica de Madrid, España. Docente e investigador del Programa de Arquitectura de la Universidad de Pamplona, Norte de Santander. Correo institucional:hgiraldo@unipamplona.edu.co. 
Palabras clave

Método, diseño participativo,

investigación, acción participativa, espacio público, centro histórico, memoria colectiva, interdisciplinariedad.

Keywords

Method and participative design, community participation, participatory action research, public space, historical center, urban memory, interdisciplinarity.

Palavras-chave

Método desenbo participativo, pesquisa ação participativa, espaço público, centro bistórico,

memória coletiva, interdisciplinaridade.

territarias 33

34

\section{RESUMEN}

La formación académica de profesionales arquitectos bajo enfoques cientificistas y disciplinares, aislados de la realidad espacial y social para la cual proyectan, como modelo de conocimiento y formación, da paso al desarrollo de una praxis contemporánea de consulta y creación colectiva, tomada por los diseñadores como punto de partida para la exploración formal de proyectos de diseño urbano concertados y de investigación social. Este proyecto de investigación formativa, con iniciativa ciudadana y académica, se basa en un método de diagnóstico y diseño participativo, para la valoración e intervención del patrimonio urbano-arquitectónico, con aplicación específica en el diseño del espacio público en el centro histórico de la ciudad de Pamplona.

\section{ABSTRACT}

Academic formation of professional architects under the scientific and disciplinary approaches isolate from space and social reality, as a model of knowledge and formation; leads to the development of a contemporary praxis of consultation and collective creation, taken by the designers as a starting point for the formal exploration of concerted urban design projects and social research. This project of formative research with civil and academic initiative is based on a diagnostic method and participative design for the evaluation and intervention of Pamplona's architectural and urban heritage, specifically applied to the design of public space, in it's historical center, based in the relationship that is built between the architects in formation and the community.

\section{RESUMO}

A formação académica de profissionais arquitetos sob enfoques cientificistas e disciplinares isolados da realidade espacial e social, para a qual projetam, como modelo de conhecimento e formação; dão lugar ao desenvolvimento de uma práxis contemporânea de consulta e criação coletiva, tomadas pelos desenhadores como ponto de partida para a exploração formal de projetos de desenho urbano concertados e de pesquisa social. Este projeto de pesquisa formativa com iniciativa cidadã e académica, baseia-se em um método de diagnóstico e desenho participativo, para a valoração e intervenção do património urbano-arquitetônico, com aplicação específica ao desenho de espaço público no centro histórico da cidade de Pamplona. 


\section{Introducción}

La recuperación y conservación del espacio público en centros históricos son responsabilidad gubernamental, tal como se formula en la Constitución Política de Colombia de 1991, que precisa: “El Estado reconoce y protege la diversidad étnica y cultural de la Nación colombiana", además establece que "es obligación del Estado y de las personas proteger las riquezas culturales y naturales de la Nación".

Bajo estos preceptos, el Ministerio de Cultura, por medio de la Dirección de Patrimonio, viene adelantando el Plan Nacional de Recuperación de Centros Históricos (PNRCH) como respuesta a la necesidad de recuperar, conservar y actualizar las funciones de los centros históricos de las ciudades con una visión de futuro, donde los cascos urbanos fundacionales actualicen sus funciones como áreas verdaderamente activas de la ciudad, donde se promueva el desarrollo de una manera sostenible desde la preservación de las estructuras existentes, complementándolas con nuevas acciones al interior de sus territorios.

Es de resaltar cómo este PNRCH involucra no solo a todas las instancias gubernamentales, sino también de manera directa a la ciudadanía y tiene como objetivo la protección y promoción de los diferentes bienes culturales declarados, entre ellos los centros históricos que son patrimonio nacional, para los cuales pretende realizar acciones de conservación, optimizar sus condiciones espaciales, ambientales y económicas mediante un enfoque sostenible e integral. Lo que genera situaciones favorables espaciales, económicas, culturales y ambientales que, aparte de contribuir a conservar las estructuras existentes, estimulen las actividades sociales, culturales y recreativas para una mayor pertenencia, identidad y valoración ciudadana de sus centros históricos urbanos, lo que hará más efectivos los derechos urbanos de estas comunidades y contribuirá a desarrollar mejores condiciones de convivencia ciudadana en el ámbito local.

Como consecuencia del citado plan, el Ministerio de Cultura Nacional decide optar por el concurso público de anteproyecto arquitectónico y urbano para la recuperación del espacio público de los centros históricos, inicialmente seleccionados por un primer programa de inversión. Dentro de sus principales argumentos, que soportan la iniciativa del concurso de diseño, se encuentran la necesidad de recuperar y conservar el legado urbano y arquitectónico y la identificación de estos centros históricos como fuente principal de recursos económicos para el desarrollo y sostenibilidad, tanto de los municipios y distritos como de los mismos centros históricos.

Para la ciudad de Pamplona, y en el desarrollo del respectivo concurso de diseño de espacio público, se seleccionaron algunas de las áreas a intervenir según el Plan Especial de Manejo y Protección (PEMP) del centro histórico, tales como el Parque Águeda Gallardo y la calle de la Universidad, buscando la obtención de un proyecto arquitectónico que garantizara calidad en la propuesta urbana y la recuperación del territarias 33

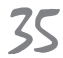


espacio público de la ciudad de Pamplona, la puesta en valor de los elementos urbanos existentes y la dinamización social, cultural y comercial de su centro histórico.

\section{Algunas experiencias de intervención de espacios públicos en entornos patrimoniales}

Esta práctica tan generalizada de realizar concursos de ideas para la intervención de espacios públicos en centros históricos o el contrato por encargo de arquitectos de prestigio para su diseño ha dejado, en la historia reciente en Colombia, una serie de hechos que ejemplifican su contradictoria implementación al desconocer la vinculación de la ciudadanía en los procesos de implementación.

El Parque Caldas, declarado bien de interés cultural de la ciudad colonial de Popayán, fue objeto de una propuesta de intervención, por parte de un distinguido profesional de la arquitectura, con recursos de Fonade y el apoyo de la alcaldía del momento. La remodelación buscó la peatonalización de las calles perimetrales al parque, pero generó resistencia por parte de los habitantes de la ciudad, mucha preocupación y extrañeza ante los alcances del diseño propuesto.

Ante esta iniciativa municipal surgieron muchas comunicaciones, cartas, documentos con origen en ciudadanos, algunas ONG, gremios de profesionales, organizaciones cívicas que demandaban una intervención pronta de las autoridades para evitar los despropósitos del proyecto próxi- mo a ejecutarse. Se pedía a las autoridades locales y de orden nacional que escucharan las opiniones de sus connotados y reconocidos arquitectos y su asociación, de la Curia Arzobispal, de la Junta Permanente Pro Semana Santa y de todos los ciudadanos que querían aportar ideas saludables y argumentar en contra de los criterios que proponía el proyecto a construir; mostrando cómo este iba en contravía del sentimiento de los payaneses y por qué se debía impedir que se atropellara el sin par y hermosísimo Parque de Caldas.

Declaraciones públicas que hacía la comunidad para no dar el aval a una propuesta de intervención meramente técnica, en cuya discusión no había tenido la oportunidad de participar, ya que esta desconocía al ciudadano común y las leyes de protección patrimonial determinadas en su declaratoria de Bien de Interés Cultural y en el Plan de Ordenamiento Territorial de la ciudad de Popayán.

Se invitaba a la comunidad a impedir la transformación de su parque patrimonial en una gran plaza, de un día para otro; a que se convocara una audiencia y se tuviera en cuenta la voluntad ciudadana, acorde con el mandato constitucional, y que el citado proyecto fuera revisado conforme a sus expectativas, a los análisis históricos, jurídicos y culturales que ameritaba este Bien de Interés Cultural; igualmente, a que se tuvieran en consideración las necesidades actuales de espacio público en la ciudad y el querer de los ciudadanos.

Otra situación representativa de este tipo de acciones urbanas es la del parque 
de Zipaquirá. El alcalde de turno propuso, mediante un proyecto de diseño seleccionado, luego de surtirse el respectivo concurso público de diseño, demoler el parque existente y, en su lugar, construir una plaza dura. Ante la oposición generalizada de la comunidad al proyecto, el alcalde ordenó, con el apoyo del expresidente Uribe, acordonar el parque a las tres de la mañana con la presencia intimidante del Ejército, para talar los árboles a escondidas de los pobladores que se oponían a que les quitaran su parque y sus sesentones árboles, que por tantos años los acompañaron. A los zipaquireños que empezaron a circular a las cinco de la mañana se dieron cuenta del atropello les prohibieron acercarse y solo se oían los angustiosos crujidos de las motosierras.

El proyecto dejó al parque desnudo, una amplia plaza despojada de criterios, de parámetros, de investigación, de comunidad, de historia y de cultura. La comunidad no entendía por qué se mutilaba el parque, por qué se destruía, si era patrimonio, y se preguntaba ¿qué mal ha hecho el parque en sus largos años de existencia? El parque, finalmente, fue demolido, con el objetivo de hacer una gran plaza dura de adobe, con el argumento de instalar una modernización minimalista o, más bien, una desnuda espacialidad.

Al definir la imagen que transmite el diseño de la plaza en el centro histórico de Zipaquirá, habrá que reconocer, rápidamente, su condición universal. Se trata de una única superficie homogénea, un ambiente sin identidad, un espacio universal, la negación de la singularidad del espacio público preexistente. Una abstracción, metafórica y precisa, en función de un sistema económico globalizado. Una propuesta de espacio público cuya única característica sea pertenecer a cualquier lugar del mundo, porque carece de expresión, de identidad.

No es una pieza de diseño urbano singular, producto de la interpretación y adecuación a unas condiciones socio-culturales y de memoria urbana colectiva, al contrario, es una pieza universal. Un espacio que no posee una narrativa propia o peculiar co- $^{-}$ mo expresión de una identidad decantada, más bien espera el acontecimiento para adquirir una narrativa. Su imagen diáfana, limpia, sin matices, es la imagen de lo que puede levantarse en cualquier lugar, que, al no representar nada en particular, pasa a representarlo todo.

\section{Los concursos de diseño}

Como se aprecia en las situaciones anteriores, el ejercicio de diseño del espacio público en centros históricos viene siendo realizado desde la creación individual, con selectos colectivos especializados, mediante encargo o por medio de concursos públicos de diseño. Donde genios creativos fundamentan la configuración reduccionista de formas, mobiliarios, superficies y decorados con una clara determinación formal y estetizante. Interviniendo de manera total las actividades y los usos preexistentes, fragmentándolos y disolviéndolos.

Estas acciones, con marcado acento funcionalista y estético, son realizadas sin territarias 33 
considerar los aspectos sociales y humanos, a partir de los cuales la memoria colectiva, el espacio público y la ciudad misma toman significación e importancia para sus habitantes.

Los arquitectos parecen haber establecido y dogmatizado un conjunto de significaciones, mal explicitado en cuanto tal y confiado a diversos vocablos: 'función', 'forma', 'estructura', o, mejor aún, funcionalismo, formalismo, estructuralismo. Lo elaboran partiendo no de significaciones percibidas $\mathrm{y}$ vividas por los que habitan sino del hecho de habitar, interpretado por ellos. Es verbal y discursivo, con tendencia al metalenguaje. Es grafismo y visualización (Lefebvre, 1969, p. 130).

El espacio público y los centros históricos condensan las acciones participativas que por largos períodos han realizado sus habitantes $\mathrm{y}$, a la par de la consolidación de dicho marco físico urbano, están asociadas con las transformaciones económicas, políticas, sociales y culturales que le han acompañado en el tiempo.

El centro histórico y su espacio público no pueden ser preservados mediante intervenciones de diseño con origen en la creación formal de un diseñador individual, simplemente porque su ejercicio se caracteriza por su particularidad excepcional, homogénea y uniforme, contraria a las complejidades que han definido dicho centro histórico. Así pues, todas las acciones con origen gubernamental o privado, de dise- centro histórico, desconocen la evolución del tejido urbano y su complejo proceso de consolidación, y en su afán de dar respuesta pronta al encargo, acaban por simplificar tan compleja realidad.

Para cumplir con su propósito reduccionista, el mero ejercicio de diseño, en el primer paso, consiste en mirar la ciudad únicamente desde su dimensión física y formal, privándola de su dimensión temporal y de su naturaleza evolutiva. El espacio público es acotado, transformado con base en estereotipos o modelos divulgados y extraídos de revistas o del gusto internacional como una estrategia de elitización del diseño, que contribuye muy poco al desarrollo articulado de las dinámicas urbanísticas, existentes.

Los concursos de diseño de espacio público, en contextos patrimoniales e históricos, tienen como lugar común un particular interés en concretar la espectacularidad, una clara intención mediática, donde la fuente de inspiración del arquitecto se ubica en contextos de la globalización. Creatividad que luego el público termina por validar mediante su difusión en los medios, buscando aclimatar su propuesta, que los jurados han seleccionado con criterios de impacto visual (la impresión causada por los dibujos renderizados), rentabilidad y poder. Tendencias que reducen al mínimo las responsabilidades sociales del ejercicio profesional.

En todo caso, estas prácticas, tan generalizadas de intervención de los espacios públicos en centros históricos, van en contravía de principios fundamentales 
señalados en la Ley General de Cultura, (Ley 1185 de 2008 y sus decretos reglamentarios), donde se han brindado herramientas para consolidar una política pública de apropiación social del patrimonio que involucra la participación de todos los actores posibles, lo que busca fortalecer las capacidades locales y hacer del patrimonio cultural el propulsor del desarrollo económico y social de las comunidades. Esta mirada integral requiere de mecanismos de participación y concertación, que apunten a la construcción de estrategias y formulación de acciones que faciliten el propósito central de las políticas de gestión, protección, salvaguarda y el disfrute del patrimonio cultural.

\section{La mal llamada participación ciudadana}

Es práctica corriente que los agentes promotores sometan a exposición pública los nuevos proyectos de intervención pública del espacio urbano, para cumplir con algún requisito de carácter general que les exige la normativa: el proyecto debe contener algún componente de participación ciudadana para que tenga un reconocimiento social, independientemente de las metodologías o alcances de este. Lo importante es que se cumpla con dicho requisito, aunque este signifique sometimiento a lo propuesto antes que participación real. ${ }^{1}$

En primer lugar, nunca se elabora y presenta a la comunidad un programa de participación ciudadana para ser ejecutado a lo largo del proceso de formulación y di- seño del proyecto. Generalmente, los procesos de participación ciudadana son muy limitados y restringidos a unos pocos grupos sociales y esta acción se realiza al final, cuando ya se ha finalizado y se encuentra dibujado el proyecto.

En algunos casos, los escenarios de exposición de los proyectos son lugares exclusivos, la exposición es de tipo informativo y se hace fuera del alcance de los grupos humanos afectados por el proyecto. En otros casos, la denominada participación ciudadana consiste en socializar o enseñar públicamente los proyectos de diseño, ya realizados, ante la comunidad, invocando el derecho a la información o a la participación, que se traduce en una exposición, a ojos del ciudadano común, en un lenguaje, técnico y de especialistas, totalmente incomprensible. Incluso, el diseño es pretendidamente descendente, puesto a la altura de los ciudadanos, cuando se permite la réplica por parte de la comunidad, pero se limita a la exposición de alegaciones, es decir, la participación se convierte en gestión de quejas y malestares generales.

Los procesos de toma de decisiones, programación y diseño de los espacios públicos han dejado al margen la opinión de los ciudadanos, la idea es cumplir, mediante algún mecanismo de socialización, con este requisito para gestionar y facilitar el ingreso de los recursos económicos que otorgan las entidades públicas y que garantizan la realización del proyecto, muy lejos de vincular a los colectivos ciudadanos con verdaderos canales de participación, que tengan en cuenta sus posibilidades reales,
${ }^{1}$ En general, existen varias formas de participación ciudadana en la gestión del espacio urbano. La topdown (de arriba abajo), la misma que practica el urbanismo tradicional, impulsado por los tecnócratas, en asocio con los dirigentes políticos y los sectores económicos dominantes, sistema al que se está acostumbrado, que ha planificado y construido gran parte de las ciudades. La formulación de acciones y politicas con destino al espacio urbano, se realiza desde arriba, desde las esferas gubernamentales, sin considerar las especificidades de los espacios urbanos, sus potencialidades de desarrollo económico, las politicas de uso y apropiación de los territorios, lo que provoca acciones que no siempre coinciden con los intereses de los ciudadanos. Un antecedente del top-down, en el diseño, se puede ver en la orientación formativa que se impartía en la École des Beaux-Arts, que consideraba que el diseño partía de un proceso individual, de un creador inspirado, que mediante el dibujo de planos determinaba los alcances del proyecto a desarrollar. $\Upsilon$ el bottom-up (de abajo a arriba), donde los colectivos ciudadanos se implican directamente, mediante una $\Rightarrow$

\section{territarias 33}


participación activa, en la planificación y diseño de los nuevos desarrollos urbanos y en la politica urbana que direcciona a la ciudad en general. A diferencia de lo que ocurre en el diseño de politicas top-down, al incorporar la participación ciudadana, en el enfoque territorial y en la toma de decisiones sobre el conjunto urbano, se alcanzan consensos colectivos, que fomentan desarrollos económicos, sociales y culturales de beneficio para el conjunto de ciudadanos. Un aporte del bottom-up, desde la formación académica, con aplicación al diseño, tiene origen en los importantes aportes en la escuela de la Baubaus, que incorporó diversas disciplinasaldiseño y, de su mutua colaboración, surgieron interesantes propuestas con aplicación a la arquitectura y el diseño industrial.

\section{territarias 33}

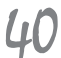

eliminando las barreras comunes de comprensión y favoreciendo la vinculación de los ciudadanos al proyecto, con base en sus posibilidades reales.

\section{La participación desde instituciones globales}

La Unesco, en la Declaración Universal sobre la Diversidad Cultural y en la Convención sobre la Protección y Promoción de la Diversidad de las Expresiones Culturales, manifiesta su interés de situar y proteger los valores de identidad, singulares y plurales, simultáneamente en el contexto global, reconociendo que la diversidad se hace manifiesta en la variedad de formas en que se expresa, enriquece y transmite el patrimonio cultural, con origen en diferentes modos de creación artística y cultural. Dicha protección es de carácter general para todas las culturas e incluye, por supuesto, las expresiones de los pueblos originarios y de las minorías.

En el mismo sentido, se expresa la Carta Cultural Iberoamericana cuando establece entre sus fines la promoción y protección de la diversidad cultural, mediante la estimulación de principios de participación, como estrategia prioritaria en el reconocimiento del origen y fundamento de las identidades culturales de los pueblos que lo conforman, con el propósito de consolidar dichos espacios culturales como un ámbito propio y singular, donde tienen expresión la memoria colectiva y patrimonial, bienes de interés cultural de carácter ancestral, en constante y masiva producción, de creatividad e imaginario incalculables.

Estas declaraciones sitúan la cultura de los pueblos en el centro de las valoraciones sociales y advierten la importancia de fortalecer sus expresiones, de hacer partícipes a todos los ciudadanos de la protección de su riqueza, entendiendo que la dimensión cultural y patrimonial no se limita a la protección a ultranza de las identidades heredadas, sino que abraca la comprensión de dichas manifestaciones culturales, como un sistema vivo y dinámico, que se recrea constantemente. Por lo tanto, la aspiración de tales declaraciones está orientada no solo a la exaltación de los valores culturales sino también a la necesidad de vincular a las comunidades a los procesos de conservación y protección, como una aspiración democrática de naturaleza compartida.

El fomento de la participación ciudadana pasa por procesos de democratización social y cultural que contribuyen a consolidar significados democráticos entre los ciudadanos, lo que genera pertenencia afectiva a proyectos compartidos, al consolidar la participación ciudadana y al recuperar la memoria colectiva, donde se podrán tomar decisiones que definan el futuro de los bienes de interés cultural y las permanencias culturales. Se entiende que cada grupo cultural, asociado con un determinado centro histórico, se identifica y representa a sí mismo a partir de lo que más valora: su memoria colectiva y urbana, sus visiones del mundo, sus tradiciones, es decir, su cultura. 


\section{Origen del proyecto de investigación formativa}

Ante la iniciativa del Ministerio de Cultura, la Alcaldía de Pamplona y la Sociedad Colombiana de Arquitectos de realizar la convocatoria al concurso público del Anteproyecto Arquitectónico y Urbano para la Recuperación del Espacio Público del Centro Histórico de Pamplona, desde la investigación académica, se advirtió acerca de la improcedencia de dicha actividad, por su condición inconsulta e impositiva en tanto desconocía las condiciones históricas y de memoria urbana del centro histórico a intervenir, así como las particulares sociales y culturales de su uso y apropiación por parte de la comunidad, al no vincular a los sujetos patrimoniales ${ }^{2}$ en las decisiones de intervención para el uso y la apropiación futura del espacio público.

En consecuencia, se formuló el presente proyecto de investigación y diseño del espacio público, propuesto para el espacio público del centro histórico de Pamplona, aplicado a dos espacios, Parque Águeda Gallardo (figura 1) y la Calle de la Universidad, que son del objeto de concurso), desde la investigación formativa y académica, es la que los participantes vinculados asumen el rol decisorio de coadyuvar a concebir el espacio público con criterios de responsabilidad social, los que se han de revertir en una mejora a la calidad de vida urbana y en la sostenibilidad de su centro histórico.

Este ejercicio académico y participativo se puso en marcha desde las aulas del taller de diseño del Programa de Arquitectura de la Universidad de Pamplona, acumuló cinco convocatorias y constituye una propuesta de actuación pública que pretende abordar una compleja y heterogénea realidad sociocultural y espacial, mediante una praxis participativa y proyectual, cualitativamente diferente de las formas convencionales de intervención y contraria a las implementadas por las acciones desarrolladas en los concursos públicos de diseño.

Desde este punto de vista, se entiende que superar estas cuestiones no solo depende de desarrollar originales metodologías de diseño participativo, sino también de modificar procesos de diseño académicos convencionales, lo mismo que la activación de valores y conductas públicas, sociales, culturales y políticas al tener como iniciativa la vinculación directa de sectores de la sociedad urbana.
Figura 1. Panorámica del Parque Águeda Gallardo

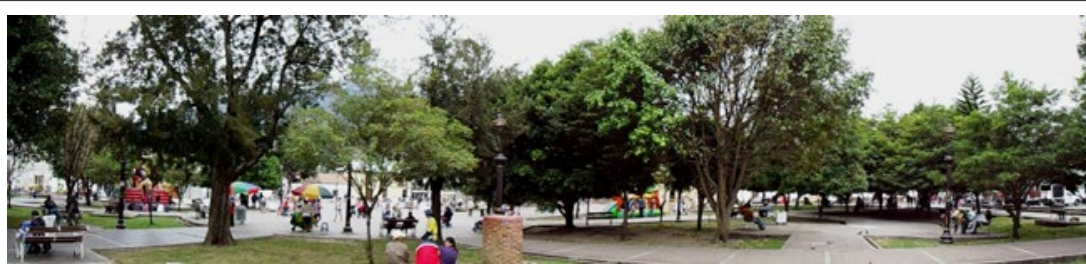

Fuente: elaboración propia.

PRODUCCIÓN SOCIAL, PROCESO PARTICIPATIVO E INTERVENCIÓN SOSTENIBLE EN EL ESPACIO PÚBLICO
${ }^{2}$ El concepto de "sujeto patrimonial" es acuñado por Fernando Carrión y se refieve a una aproximación empirica al patrimonio de los centros históricos, que admite que si existen sujetos (entidades, ONG, instituciones, organismos, comunidades, propietarios, culturas, personas) que dan uso cotidiano, apoyan $y / 0$ reconocen un entorno o un espacio arquitectónico como un bien patrimonial, dichos colectivos podrán ser identificadas como "sujetos patrimoniales" de acuerdo con el nivel de incidencia y compromiso en el proceso de producción, apropiación y defensa de dicho centro histórico, objeto de referencia. Desde este punto de vista las colectividades ciudadanas, públicas o privadas, comerciales, económicas, institucionales, gubernamentales y culturales, que usufructuan, apropian, reconoceny defienden un centro histórico, podrian ser consideradas como "sujetos patrimoniales” del centro histórico objeto de su apropiación.

territarios 33 41 
participativo y la participación ciudadana, en el diagnóstico y formulación de soluciones espaciales al espacio público en el centro histórico de la ciudad de Pamplona, que comprende la observación de su realidad, generar la reflexión colectiva y participativa sobre su estado y ofrecer soluciones de planificación y diseño de su espacio público para evitar su deterioro, construir identidad y pertenencia ciudadana, mejorar y exaltar su entorno patrimonial y arquitectónico y hacer ciudad.

¿Cómo no defender la necesidad de articular mecanismos múltiples de democracia local participativa o deliberativa, de cooperación social, de consenso sobre los proyectos urbanos, de solidaridad ciudadana, de civismo para hacer posible la convivencia, de colaboración activa para una gestión sostenible? (Borja, 2010, p. 91).

En este caso la Investigación Acción Participativa (IAP) es tomada como herramienta para desarrollar el proceso de participación, insertado en una estrategia de acción definida: involucrar a los sujetos patrimoniales, que hacen uso del espacio público de manera cotidiana, como inspiradores y poseedores de la memoria colectiva y como actores y beneficiarios directos del proceso de producción colectivo del espacio y generadores de los conocimientos necesarios para transformar una determinada realidad espacial, social, ambiental y cultural.

\section{territarias 33}

42
Las bases de esta decisión holística son conocidas: hacer investigación participativa es aceptar que toda investigación sea interacción comunicante, en la que ocurre un proceso de diálogo de aprendizaje mutuo y de mutua confianza entre el investigador y el investigado. En este proceso se invalida la división tradicional entre conocimiento objetivo y subjetivo; se afinan o complementan pautas normales de medición y análisis de la realidad; se equilibran los intereses teóricos del observador externo y de los actores locales que quieren transformar la práctica diaria, y se practica la interdisciplina. El resultado viene a ser tan calificado y respetable como el que se aduce para la investigación tradicional. Y el investigador, como parte de la realidad investigada, se convierte en actor comprometido que debe a su vez analizarse y ser analizado (Borda, 1998, p. 173).

La IAP permite articular los diferentes conocimientos disciplinares para dar solución a un problema de diseño de espacio público, lo que aumenta las competencias de los respectivos participantes al ser realizada mediante participación colectiva, utilizando la información en un proceso cíclico, en tal sentido la IAP, permite:

- Hacer eficientes los procesos de participación y comunicación interpersonal, identificando las organizaciones sociales de asociación colectiva, vigentes del entorno y conformar los grupos de trabajo.

- Contribuir a concienciar a la comunidad con su propia realidad, identificar sus necesidades y determinar los factores que la afectan. Seleccionar los temas 
de trabajo y sus enfoques según el nivel de compromiso de los grupos participantes. Articular consultas colaborativas y alcanzar formas de comprensión consensuadas, cualitativas y hermenéuticas que capaciten a los colectivos en la toma de decisiones.

- Hacer posible el trabajo inter y transdiciplinario en un proceso integral, continuo y colaborativo con la participación activa de la comunidad durante todo el proyecto, la cual, mediante la comunicación, posibilita el intercambio permanente de conocimientos y experiencias y descubre las decisiones de intervención.

- Identificar y hacer valer los resultados de procesos concertados que permitan elegir respecto de las determinaciones de poder, para dinamizar las acciones e implementar prácticas más justas.

La IAP es un esquema sencillo que permite conocer, comentar y negociar en consenso para proponer programas de intervención en el espacio público; conectando la investigación y el conocimiento del espacio a su posterior intervención, mediante la vinculación de las necesidades colectivas con las acciones consensuadas.

Hay varias razones para actuar así: desde la cotidianidad, los habitantes de la ciudad son los que mejor conocen los problemas de espacio público y del centro histórico. Al tomar parte en procesos de sensibilización, valoración e intervención de su centro urbano patrimonial, los ciudadanos renuevan también su autoestima como actores en su propia ciudad. Con lo cual se contribuye a la reinvención de la identidad simbólica local, convirtiendo en positivo y motivo de orgullo lo que viene siendo transformado para beneficio de sectores privados.

La IAP es una metodología en la que los sujetos patrimoniales son coinvestigadores y codiseñadores del espacio público, participando activamente en el planteamiento del problema, en la información que se debe obtener para su solución, en los métodos y técnicas que van a ser utilizados, en el análisis e interpretación de los datos y en la decisión de las acciones a implementar para la intervención futura de dicho espacio público. Los investigadores de otras disciplinas participan como facilitadores y pedagogos del proceso, como catalizadores de problemas y conflictos y, en general, como técnicos o recurso disponible para ser consultado.

Mediante este ejercicio académico y ciudadano se aproxima el conocimiento práctico que del espacio público tiene la comunidad, involucrando a los ciudadanos en la sistematización de sus vivencias y memorias colectivas, en el acopio de sus experiencias de uso y apropiación; acercándose al conocimiento de los valores atribuidos y explorando los anhelos de las comunidades acerca de su intervención. A partir del proceso de investigación - acción - participante, se explora el conocimiento de la realidad urbana y se fortalece el empoderamiento social. Las comunidades, en el ejercicio de participación ciudadana para la intervención del espacio público, territarias 33

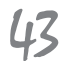


establecen una conexión efectiva entre producción de conocimiento, su traducción a intereses compartidos y el derecho a intervenir colectivamente el entorno y realizar los cambios necesarios, en la lucha permanente por afirmar el derecho a la ciudad y su sostenibilidad.

\section{Aportes de la investigación etnográfica}

El entorno humano del centro histórico de Pamplona, y el de su espacio público, es una unidad social que puede ser estudiada etnográficamente. Mediante la etnografía es posible alcanzar la descripción realista y fiel del estilo de vida de este colectivo humano y, por lo tanto, la comprensión de su realidad actual, de sus acciones, de los usos y formas de percepción y representación del espacio público determinado.

El colectivo ciudadano, en este caso, es la comunidad urbana de Pamplona, cuyas relaciones están reguladas por las prácticas sociales, culturales y económicas, así como por los derechos y obligaciones que comparten, lo mismo que por sus tradiciones, su historia común, los marcos y sitios de la memoria colectiva. Regularidades que pueden explicar la conducta individual y de grupo en forma adecuada, mediante estudios analíticos descriptivos de sus prácticas culturales y religiosas, conocimientos y creencias, comportamientos particulares del colectivo humano.

Las herramientas de la investigación tersitarias 33 44 etnográfica pueden ser la cinematografía, las grabaciones sonoras, la fotogrametría, la elaboración de mapas. El éxito de la investigación etnográfica dependerá de la habilidad con la que se clasifiquen he interpreten los hechos urbanos observados.

En tal sentido, mediante la investigación etnográfica se podrían tratar de entender las actitudes, comportamientos en el espacio público y la incidencia biunívoca entre la estructura de ese espacio público, los colectivos y las individualidades, como si fuese una proxemia, donde se estudian conceptos como las territorialidades cotidianas, el uso y la apropiación del espacio, estableciendo predominancias, relaciones formales, jerarquías de uso, periodización, marcas de dominio, entre otros.

La intervención del espacio público debe considerar las identidades sociales y culturales, las preferencias al medio construido por parte de los colectivos ciudadanos, para acogerlas en el proceso de intervención, teniendo en cuenta que el medio físico puede ser un instrumento de separación o de delimitación, de integración o de protección y que de su conocimiento o de su adecuada interpretación fenomenológica, depende, en buena medida, el éxito de las acciones acordadas para la composición de dicho espacio público, las que, en perspectiva de una adecuada intervención espacial, deberán consolidar y/o agregar valor cultural al espacio y las manifestaciones sociales preexistentes.

Con toda la información adquirida de la comunidad y los inventarios obtenidos de la observación participante, se tienen insumos importantes para el diseño urbano, se inician procesos de concreción pro- 
gramática del espacio público, a los cuales incorporamos los análisis físicos del espacio público, formas, usos, flujos y modalidades de uso, imagen y representación, materialidad, entre otros, los cuales interactúan, a veces de manera azarosa, hasta conformar el campo propicio para la creación.

Mediante la observación participante, un recurso disciplinar con origen en la etnografía y la sociología, se complementan los resultados obtenidos de los talleres de diseño participativo. Para lograr una intervención y diseño adecuado del espacio público, es necesario observar y entender las relaciones entre las formas de apropiación y uso que los colectivos sociales e individuales le dan actualmente a este y su relación con las estructuras, formas y tipos de espacios donde tienen asiento estas expresiones humanas (figuras 2 y 3 ).

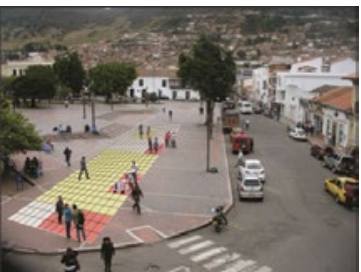

Fuente: elaborado por Wilson Hernández.

Nota: La identificación del nivel de apropiación del espacio público se registra de manera descriptiva y consiste en identificar actividades y acontecimientos frecuentes protagonizados por los habitantes en el espacio público, para lo cual se desarrolla un sistema de indicadores de permanencia y de frecuencia de uso de los lugares donde dichas actuaciones tienen ocurrencia, trasladando a planimetrías del espacio público, la localización de patrones de comportamiento.

Entender las interrelaciones entre las personas, la gente o el pueblo, por un lado, y el medio físico urbano, por el otro. Estas relaciones pueden analizarse empíri-

Figura 2. Zonas de uso del parque Águeda

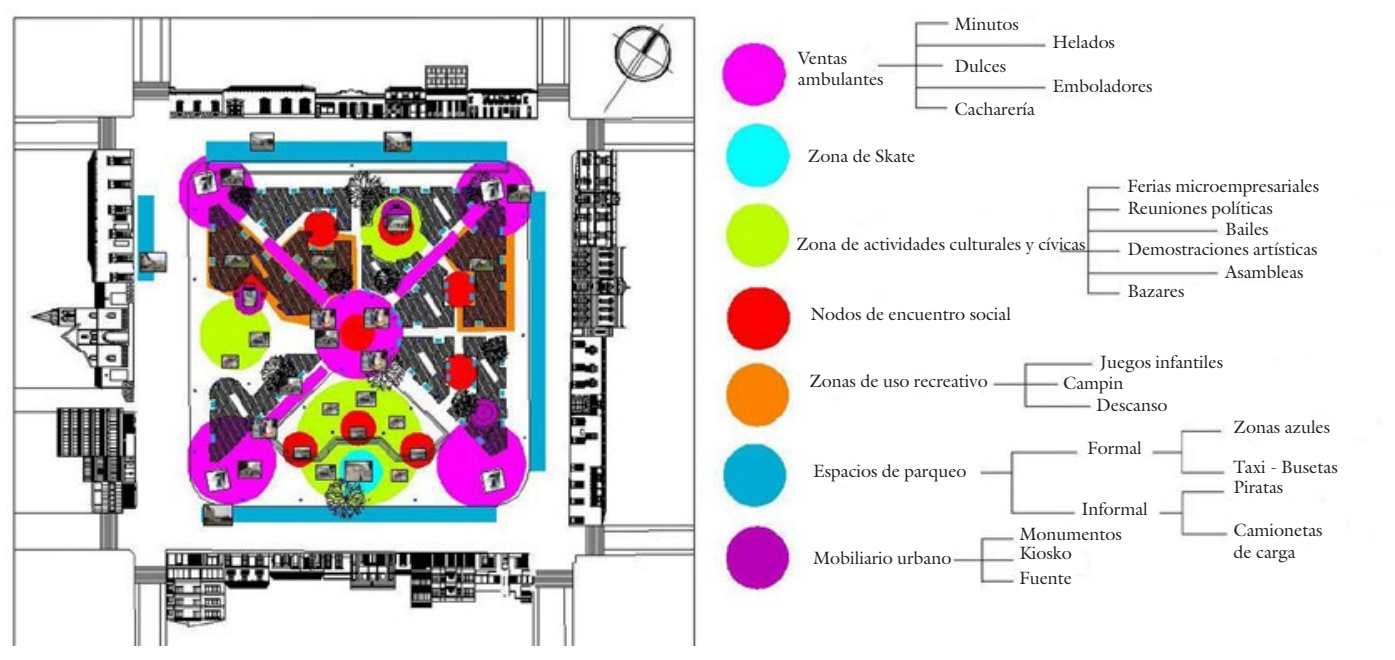

Fuente: elaborado por Hinostroza y Gallardo. 
camente solo cuando se estudian tal como ocurren, se tienen los argumentos (ideas fuerza) para entender, diseñar o intervenir ese medio construido, sin destrozar la cultura y con ello expoliar la memoria colectiva y las actividades de sus gentes.

Esta estrategia de aproximación empírica al espacio público, mediante la observación participante que ofrece la etnografía y su aplicación a los espacios o a los escenarios, donde se expresan los colectivos humanos, significa un aporte a su estudio y diseño desde una perspectiva cultural y una contribución a su sostenibilidad.

\section{El trabajo interdisciplinario}

La creación colectiva del espacio público consiste en un proceso comunicativo, se basa en la filosofía pragmática, que busca apoyar la función primaria del planificador y diseñador, a partir de escuchar los relatos e imaginarios de la gente y asistir al proceso de narración, identificación y construcción de consensos entre los diferentes puntos de vista, respecto del entorno urbano.

Desde el punto de vista social y antropológico, la investigación le apuesta a la ciudad equitativa y a la observación participante, al destacar la importancia del uso que la comunidad realiza del espacio público y el contacto físico que la comunidad establece con los elementos que lo conforman. Bajo este concepto, se obtiene valiosa información del espacio urbano y las formas de apropiación y uso que de él hacen los sujetos patrimoniales, en las
Si bien, los arquitectos procuran desarrollar una adecuada propuesta morfológica y una mejor ciudad, desde el estudio de las formas urbanas, este proyecto de investigación consiste en vincular los aspectos históricos, de memoria colectiva, social, cultural y ambiental, que estructuran los procesos que le dan sentido y sostenibilidad al espacio urbano.

El uso de diversos modelos conceptuales disciplinares enriquece la metodología de estudio, de diseño y de intervención de los espacios colectivos y la orientan hacia una concepción antropológica del espacio público. Sin embargo, no hay diseño urbano sin las instancias disciplinares de la arquitectura y el diseño. El hecho de que el proceso sea participativo e interdisciplinar no significa que los diseñadores no sean protagonistas importantes de la propuesta final de espacio público.

\section{El rol de la memoria colectiva}

En este campo de la investigación, se acude a los aportes del sociólogo francés Maurice Halbwachs, quien propuso y desarrolló el concepto de memoria colectiva. Halbwachs (2004), al precisar las formas de vinculación de los individuos y de los grupos con los espacios y objetos del entorno, planteó cómo los colectivos ciudadanos se autorreferencian entorno al marco que han construido colectivamente. Lo que demuestra, por una parte, la capacidad que tienen los individuos y grupos colectivos de transformar y construir la imagen del entorno exterior y, al mismo tiempo, la predisposición del 
grupo a someterse y adaptarse a espacios físicos que perpetúan conscientemente o permanecen, en el tiempo, como referente de una identidad compartida:

No cabe duda de que la diferenciación de una ciudad es el origen de diversas funciones y costumbres sociales; pero, aunque el grupo evoluciona, el aspecto exterior de la ciudad cambia más despacio. Las costumbres locales se resisten a las fuerzas que tienden a transformarlas, y esta resistencia permite percibir mejor hasta qué punto en estos grupos la memoria colectiva se apoya en imágenes espaciales (Halbwachs, 2004. Pág. 136).

El ejercicio de aproximación a la memoria colectiva no consiste en reconstruir acontecimientos, hechos o espacios olvidados, sino en invocar un presente activo al que confluyen recuerdos sociales y culturales que contribuyen a la consolidación de una conciencia colectiva que permita identificar acciones en el entorno, que atiendan o den soluciones a las necesidades de la comunidad. La memoria colectiva tiene una importante influencia para el diseño del entorno, tal como lo han sido los análisis urbano-arquitectónicos disciplinares aplicados en su estudio. Su vinculación es el baluarte que posibilita el proceso de toma de decisiones, de programación espacial en la búsqueda colectiva de un diseño de espacio público, que será el marco físico de la memoria elegido y que se precia de contemporáneo.

El uso de la memoria colectiva como fuente de información y como objeto de investigación, especialmente en los procesos de intervención del espacio público en centros históricos, la convierte en una herramienta insoslayable de uso útil para el diseñador urbano contemporáneo, garantizando, previamente, la verificabilidad de sus logros. La memoria colectiva tiene un valor social y cultural importante $y$, en este caso, se complementa con aportes disciplinares de diferentes fuentes de conocimiento, asociados con el diseño urbano, que refiere el discurso construido, contrastable y objetivado, sujeto a métodos disciplinares. La memoria colectiva pone en evidencia los valores del pasado, presente y futuro sociocultural del grupo ciudadano y el diseño urbano es quien los incorpora.

Si entre las casas, las calles y los grupos de habitantes, no hubiera más que una relación accidental y de corta duración, los hombres podrían destruir sus casas, su barrio, su ciudad y reconstruir otros, en el mismo lugar, según un plano distinto. Pero aunque las piedras se dejan transportar, no es tan fácil modificar las relaciones que se han establecido entre las piedras y los hombres. Cuando un grupo humano vive durante mucho tiempo en un lugar adaptado a sus costumbres, no solo sus movimientos, sino también sus pensamientos se regulan según la sucesión de imágenes materiales que le ofrecen los objetos exteriores. Ya se pueden suprimir en parte o modificar la dirección, la orientación, la forma o el aspecto de estas casas, estas calles, estos pasos, o cambiar solamente el lugar que ocupan uno respecto de otro. Las piedras y los materiales no se resistirán. Pero los grupos se resistirán territarias 33

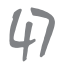


y, en ellos, se enfrentarán, no tanto al apego a las piedras, como al que tienen a sus antiguos lazos (Halbwachs, 2004, p 137).

El diseño del espacio público cumple un importante papel en la construcción de la memoria colectiva, en la medida en que sus propuestas de intervención y diseño permitan corregir aquellos datos del pasado que la investigación encuentra alterados y sobre los que se construyen y validan memorias de encuentro sociocultural. El papel del diseño urbano en la configuración del marco físico de la memoria no supone establecer una correcta y verdadera intervención de diseño formal, es el proceso de aval, mediante el método de consulta y consenso colectivo, el que le otorga sentido y validez frente a las posibles deformaciones de la memoria. En este sentido, se entiende que el diseño del espacio urbano es resultado de un proceso de valoración y selección con grados importantes de subjetividad, pero que estará soportado en la consolidación de las valoraciones colectivas de la memoria urbana (figura 4).

La incorporación de la memoria colectiva al proceso de diseño del espacio público como instrumento útil para identificar, incorporar y forjar las identidades colectivas, viene de la mano para menoscabar el diseño puro y duro, porque este no prevé o no incluye los aspectos sociales asociados con el uso y apropiación colectiva del espacio en la dimensión espaciotemporal.

Antes del uso prolífico actual de la vertiente técnica y estética del diseño del espacio público en sistemas de programación,
Figura 4. Exposición maqueta de Pamplona (1890) en la Calle Real

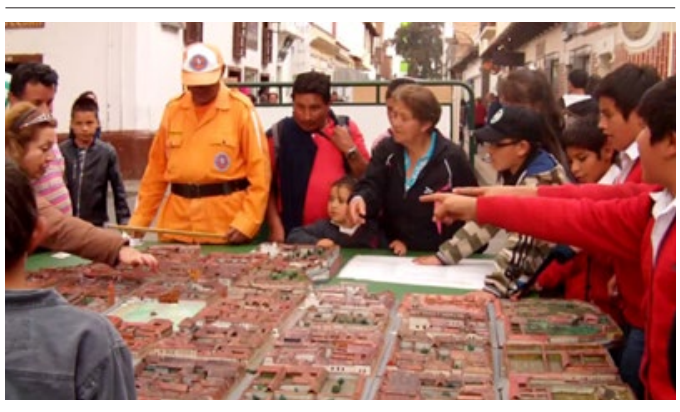

Fuente: elaboración propia.

Nota: Maqueta Así era Pamplona en 1890 del Museo Toto Villamizar, es expuesta en la Calle Real, en el marco del $2 .{ }^{\circ}$ Calleralazo, para ambientar con la ciudadanía el Escenario Pasado de la ciudad, traer a presente el pasado y valorar aspectos de la memoria colectiva de la ciudad, un componente esencial de los TDPE.

datos físico-espaciales y las especulaciones formales para su intervención, habrá que reconocer que, desde el siglo pasado, se han venido extendiendo los estudios de la memoria desde la psicología cognitiva a la filosofía (Nietzche, Bergson, Benjamin, Ricoeur), la literatura (Proust), la sociología (Halbwaschs), la antropología (Candau) o la historia (Nora, Le Goff, Le Roy Ladurie), disciplinas que han ido mostrando un interés creciente por la cuestión de su relación con la experiencia individual y colectiva.

Historiadores, psicólogos y sociólogos reconocen que la memoria es un asunto de suma importancia, que está estrechamente vinculado entre otros múltiples asuntos, con las formas de relación personal y colectiva del espacio público. Reconocen que los individuos construyen y reconstruyen continuamente sus experiencias con el lugar, 
de modo que sus memorias representan un acto de ensamble y de reaprendizaje. Hay que transformar la actual desconfianza y desprecio de los diseñadores hacia la memoria colectiva e introducirla en el corazón de las disciplinas de intervención del espacio-tiempo, como una categoría de uso habitual, por encima de las demoledoras críticas de los diseñadores del movimiento moderno y del posmodernismo, que hicieron críticas a los aspectos totalizadores y cientificistas del diseño.

El recurso de la memoria colectiva se convierte en una fuente alternativa de conocimiento, que complementaría y justificaría muchas de las decisiones de diseño, gracias a su capacidad para vincular la emotividad, la percepción y la empatía de los usuarios y colectivos ciudadanos con sus entornos; especialmente cuando estos condensan historia y experiencias sociales como los centros históricos urbanos (figura 5). Dada la importancia que la cultura actual da a la función social de la memoria, es innegable su extraordinaria relevancia en las formas en que hoy percibimos e intervenimos el entorno urbano, lo que no solo implica un aumento de la conciencia histórica, sino también, en la lucha política en la recuperación y exaltación de las identidades ciudadanas.

La memoria colectiva no solo es el término líder en la nueva historia cultural, sino que también está invadiendo con fuerza otras disciplinas como la historia social y política, al incorporar en sus estudios las tradiciones colectivas, las de clase, las etnias regionales, las de los partidos o las de
Figura 5. Sensibilización de la memoria colectiva en la Calle Real

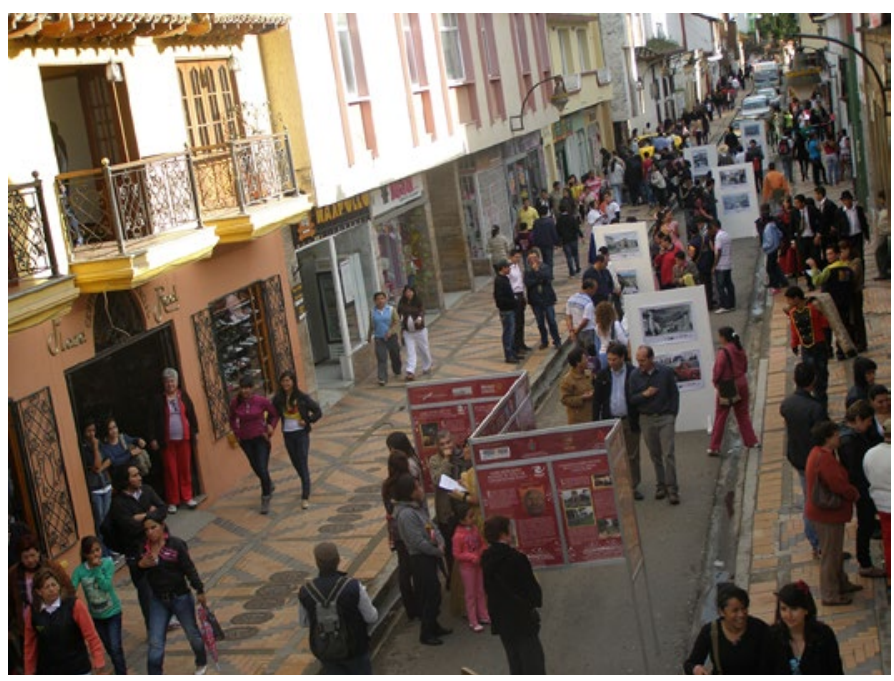

Fuente: elaboración propia.

Nota: El Callerealazo, es un evento cultural que ya se ha institucionalizado (va en su $5 .^{a}$ versión) consiste en cerrar el tráfico vehicular de la Calle Real de Pamplona (una tarde) y abrirla al uso peatonal exclusivo, lo que promueve la realización de múltiples actividades culturales, con el fin de sensibilizar, valorar y proteger el patrimonio urbano-arquitectónico de la ciudad. El Callerealazo surgió como una propuesta de los TDPE para recuperar y reivindicar la memoria colectiva, diagnosticar y hacer encuestas de percepción y opinión ciudadana sobre el problema de espacio público. Luego, para exponer y evaluar los anteproyectos de diseño de espacio público, elaborados por estudiantes de arquitectura, con base en las determinantes construidas colectivamente desde los TDPE.

la guerra, que vienen siendo incorporadas por la gestión pública, por las autoridades, por los historiadores o por los activistas de la memoria.

Estas cuestiones se plantean por culpa de las confusiones existentes en torno a la percepción del pasado y a la naturaleza del inacabable proceso de cambio del entorno, así como por los desacuerdos existentes respecto a la finalidad de la preservación. La memoria no puede retenerlo todo; si pudiera, nos aplastarían los datos. La memoria es el resultado

territarios 33

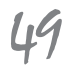




\section{territorias 33 hace visibles muchos de los problemas que normalmente permanecen ocultos.}

de un proceso de selección y organización, resultado que se elige de modo que quede dentro del marco de las situaciones previsibles. Deben existir también algunas acumulaciones aleatorias que nos permitan descubrir relaciones inesperadas, pero la afición a las antigüedades es posible solamente cuando la recogida de datos consiste esencialmente en retener lo significativo y rechazar lo no significativo (Lynch, 1975, p. 42)

La construcción de la memoria colectiva es un insumo fundamental que permite incorporar al proceso de diseño del espacio público, el entorno y los sujetos históricos, independientemente de lo que significaron en su tiempo y del que se pueden extraer fragmentos para (re)construir el presente, según los intereses de los ciudadanos, en un recurso de consulta como vía privilegiada hacia el pasado y como reivindicación de la presencia del pasado en el presente.

La memoria colectiva y el diseño del espacio público, aunque no son convergentes en su naturaleza, la relación entre ambas es contingente. El apoyo actual a la memoria no tiene un efecto pernicioso en el diseño, su influencia mutua circula entre vasos comunicantes. La aplicación emergente del diseño, en este binomio que conjuga lo social con el espacio público urbano, hace del diseño una herramienta útil para la cohesión y transformación social. Mediante la combinación holística de varios tipos de disciplinas y aplicaciones aborda un diseño de espacio público, que
En esta perspectiva hay que utilizar nuevos instrumentos que posibiliten una propuesta democrática y participativa de base social, en la que la propia población establezca las coordenadas principales que van a proyectar el futuro de su espacio público en el centro histórico. Mediante el compromiso con la memoria colectiva se podrá reivindicar una verdadera participación (figura 6).

Figura 6. Entrevista en profundidad a personajes notables

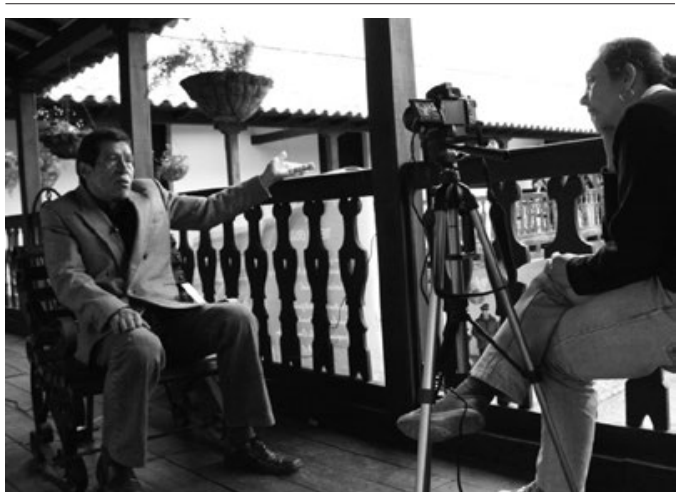

Fuente: elaboración propia.

Nota: Entrevistas en profundidad (video) hechas a personajes notables que aman y conocen profundamente la ciudad y tienen un especial interés en su patrimonio tangible e intangible, en la cultura y en el desarrollo urbano, constituye un componente fundamental de la consulta ciudadana y el proceso participativo, enriqueciendo sustancialmente las decisiones de diseño.

La restauración es injusta a menos que los residentes actuales puedan elegir entre quedarse en las estructuras renovadas o marcharse. Si hacen lo primero, la renovación es un asunto muy distinto pues los residentes ven valores distintos y una historia muy diferente en las viejas casas. A menudo fueron sus ante-

Huber Giraldo Giraldo 
pasados los que construyeron en realidad esas hermosas casas, y en los años más recientes la historia de ese lugar ha sido, desde luego, suya (Lynch, 1975, p. 49).

Con toda la información adquirida de la comunidad y todos los elementos necesarios para el diseño urbano, interactuando a veces de manera azarosa, se conforma el campo propicio para la creación. El papel en blanco comienza a ser reemplazado por la información que, desplegada ante los ojos de los arquitectos en formación, estimulará el proceso creativo, obteniendo soluciones parciales en las que nunca se hubiese pensado, al tratar de obtener la solución lógica procediendo, como es habitual, en línea recta. Se ha estimulado la mente con ideas, se la ha liberado por caminos distintos, con el fin de romper la idea concertada.

Una de las conclusiones de los talleres de diseño participativo consiste en alcanzar los indicadores cualitativos y cuantitativos que permiten identificar los aportes de los grupos involucrados y los alcances de las propuestas desarrolladas, dando a los grupos la posibilidad de construir cultura de participación y la adquisición de experiencias que los harán mayormente autosuficientes. Alcanzar mayor satisfacción social en las comunidades y una valoración de las actividades de los arquitectos haciendo esta profesión útil y creativa al servicio de las comunidades.

Tan problemática como la propia doctrina de la preservación es la definición de su finalidad ¿qué piezas del entorno debemos intentar reconstruir o conservar, y cuáles no? ¿Buscamos pruebas de los momentos estelares o cualquier manifestación de la tradición que podemos encontrar, o estamos juzgando y evaluando el pasado, eligiendo lo más significativo en detrimento de lo menos, conservando lo que consideramos es mejor? ¿Deben salvarse las cosas porque están asociadas a personas o acontecimientos importantes? ¿Porque son únicas o casi únicas o, por el contrario, porque son las más típicas de su tiempo? ¿A causa de su importancia como símbolo colectivo? ¿A causa de sus cualidades intrínsecas en el presente? ¿A causa de su especial utilidad como fuente de información intelectual sobre el pasado? ¿O debemos limitarnos simplemente (como hacemos tan a menudo) a que el azar haga la elección por nosotros y preserve para un segundo siglo todo aquello que por casualidad ha sobrevivido el primero? (Lynch, 1975, p. 41).

\section{Metodología general}

La metodología para el desarrollo de un proyecto de diseño de espacio público con participación ciudadana es integral e interdisciplinaria, establece un sistema de participación entre actores ciudadanos, técnicos del diseño urbano, diversas disciplinas del conocimiento y representantes institucionales, con lo que se alcanzaría a elaborar diagnósticos y estrategias de intervención del espacio público. Donde uno de los pilares es el protagonismo de los actores sociales, de los sujetos patrimoniales de la ciudad, desde la participación territarias 33

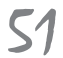


ciudadana, entendiendo por tal la capacidad que tienen estos actores para influir en el diseño, ejecución y evaluación de las políticas y programas públicos destinados a valorar e intervenir el espacio público en su centro histórico.

El diseño participativo se propone como una forma de desarrollar arquitectura y diseño urbano, basado en los aportes que hace la comunidad en talleres interactivos estructurados por escenarios espacio-temporales y sistematizados mediante relatorías, escritos y gráficos (figura 7). Resultados que se toman como insumos para el desarrollo de propuestas urbanoarquitectónicas. En tal sentido, los profesionales del diseño urbano representan un papel de mediadores entre ciudadanos, comunidades e instituciones gubernamentales, en un proceso colaborativo que tiene como objetivo conectar a estos tres actores sociales y dar respuesta espacial y de diseño urbano a los anhelos de quienes actúan en estos entornos.

Aunque no es viable catalogar el ejercicio de diseño urbano dentro de los parámetros específicos establecidos para la identificación de las disciplinas científicas, en este caso, mediante el recurso cognitivo de la analogía, guardando las proporciones entre semejanzas y diferencias, se trasladan los procedimientos de la investigación científica al ejercicio de diseño.

El proyecto de diseño urbano-arquitectónico, estructurado desde esta lógica, adquiere las condiciones de un proceso

\section{territarias 33}

Figura 7. Proceso de investigación proyectual

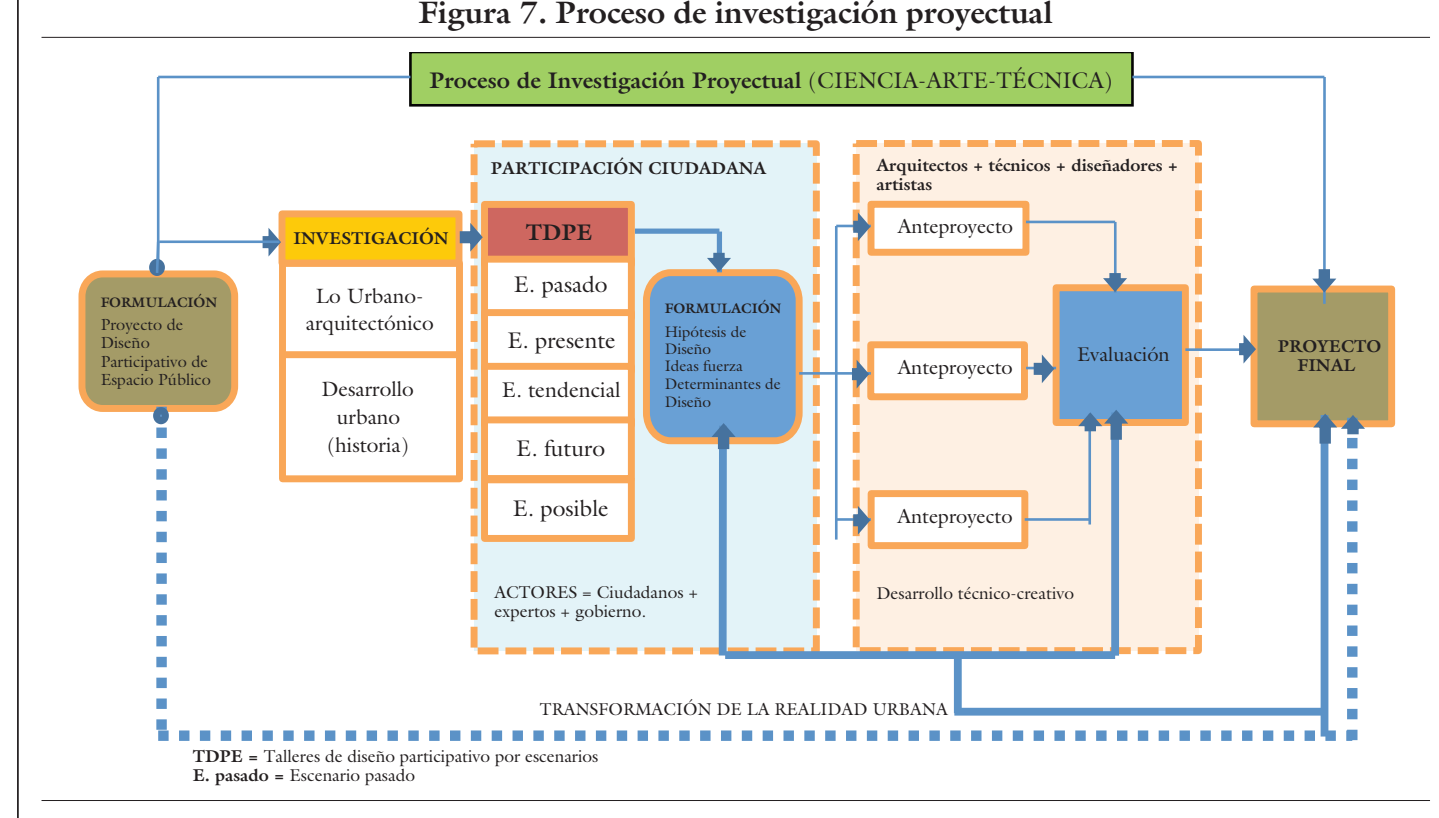

Fuente: elaboración propia. 
de construcción de conocimiento, que no solo permite tomar distancia respecto de la forma convencional en que se asume el oficio de proyectación, como una actividad puramente creativa, soportada en la exclusiva búsqueda formal y estetizante de la propuesta final, sino también ampliar su campo de dominio y de aplicación.

Las asistencias suministradas por otras disciplinas sociales y áreas del conocimiento, como la etnografía, la memoria urbana, la comunicación, la geografía social, los mapas mentales, los estudios de pros- pectiva y el diseño participativo, permiten adoptar una postura de análisis integral e interdisciplinar, orientada a reconciliar el proceso creador del espacio, propio de la disciplina proyectual, con la realidad social, ambiental y cultural del espacio objeto de intervención. Este sistema creativo fusiona comunicación, información, vivencia y conocimiento en una serie de talleres públicos que generan diálogos entre habitantes, disciplinas del conocimiento, arquitectos y espacio público (figura 8).

Figura 8. Actores y disciplinas claves del proceso

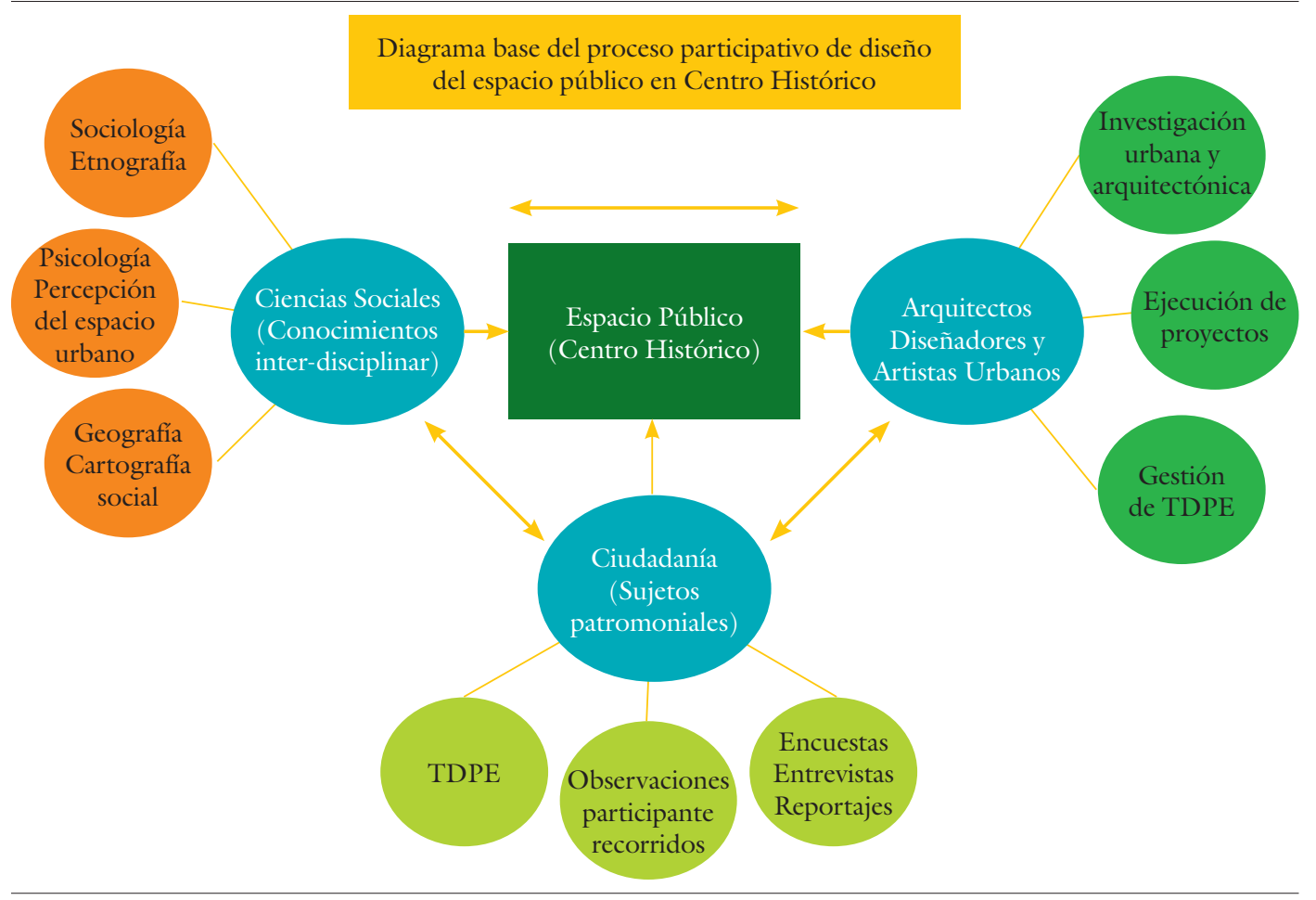

Fuente: elaboración propia. 


\section{Dimensión metodológica}

En el entendido de que el ejercicio de proyectación y las formas espaciales que subyacen a él surgen de un programa o de un plan de abordaje, se adopta el método racional hipotético-deductivo como modelo objetivo y racionalista, lo que supone revisar los conceptos y significados inherentes al acto de proyectar, reconociendo sus particulares componentes teóricos que le dan el sustento y la dimensión metodológica que permite recorrer un camino en el que se va dilucidando el objeto de creación.

Con la identificación y clasificación de la información obtenida del proceso de los talleres de diseño participativo por escenarios: la observación participante, las encuestas de percepción ciudadana, la cartografía social, los esquemas de relaciones, las entrevistas en profundidad y los aportes documentales de la investigación suministrada desde los conocimientos disciplinares, se construyen matrices de investigación que relacionan componentes y dimensiones que definen el programa de intervención, las hipótesis de diseño, tipologías y topologías, que luego son tomadas por los técnicos y profesionales para el desarrollo de anteproyectos alternativos, los cuales, a su vez, son nuevamente evaluados por los ciudadanos a la luz de las hipótesis y programas de diseño, mediante estaciones públicas de consulta ciudadana.

Es importante señalar que este ejercicio de aproximación colectiva a anteproyec-

\section{territorias 33}

sistema de feed back positivo, que asegura la vinculación de todas las variables, los anhelos y necesidades de los ciudadanospermite depurar el proceso en la materialización de las soluciones proyectuales, conforme con los enunciados generales, que deberán ser comprobados con el proyecto de diseño. Los resultados alcanzados se podrán explicar independientemente de los alcances formales de los espacios diseñados, elementos o componentes que intervienen.

\section{Los talleres de diseño participativo por escenarios (TDPE)}

El diseño participativo por escenarios espacio-temporales es una técnica ideada a partir de la planeación prospectiva y la metodología de investigación - acción - participación, que se ha ajustado a las particulares condiciones del diseño urbano y que es utilizada para la construcción consensuada de alternativas de intervención y diseño de espacios públicos urbanos, mediante consenso ciudadano. Al considerar los escenarios espacio-temporales de pasado, presente y futuro, no solo se conoce el proceso de evolución del espacio en el tiempo, se identifican las preexistencias físicas sociales y culturales, se investigan y conocen las de la realidad urbana con mayor profundidad, sino que, se evitan errores de interpretación u omisiones imperdonables en la toma de decisiones, relacionadas con valores culturales y patrimoniales de especial relevancia patrimonial y de la memoria colectiva para los ciudadanos. 


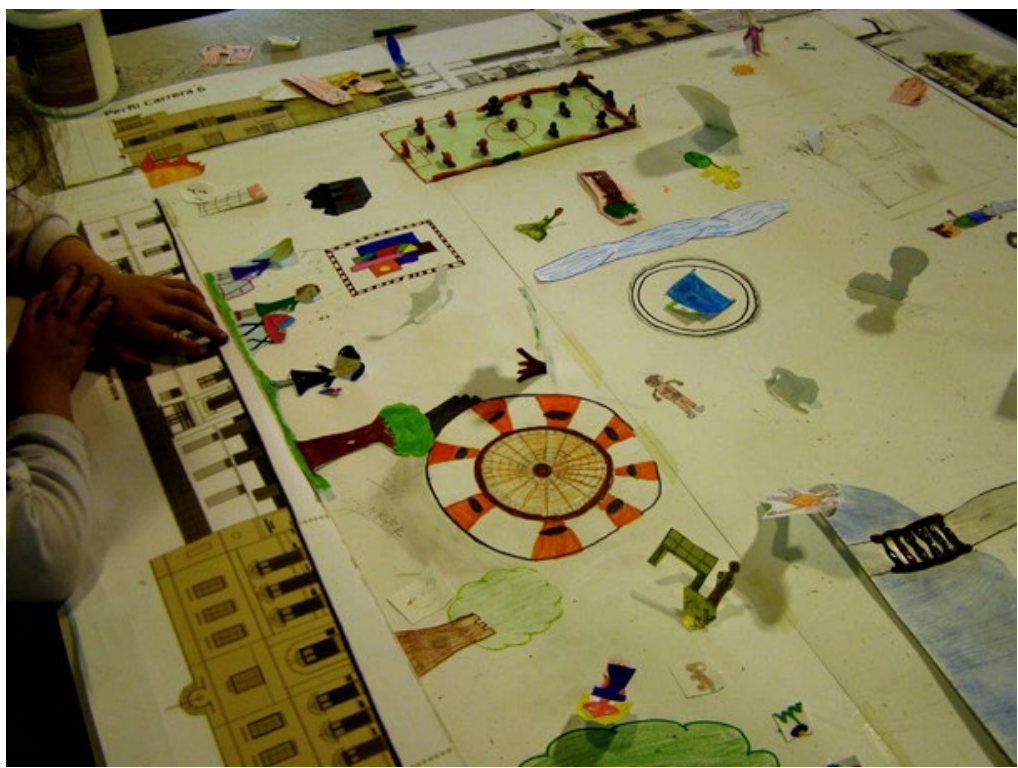

Fuente: elaboración propia.

Nota: Niños de Pamplona se vincularon a la experiencia de los TDPE del Parque Águeda, desarrollando diagnóstico participativo, foto-etnografía, propuestas programáticas y de diseño con base en sus necesidades, sus anhelos y las experiencias vivenciadas del lugar.

La técnica del taller de diseño por escenarios significa construir colectivamente visiones múltiples y dinámicas por parte de los colectivos ciudadanos acerca del espacio y el entorno objeto de intervención (figura 9). En sí mismo es un vehículo para construir pensamientos e ideas de intervención en el centro histórico con perspectiva de futuro. El objetivo inmediato de los talleres de diseño urbano por escenarios consiste en producir narraciones (orales, escritas, dibujadas, etcétera) basadas en la evocación y simulación del espacio objeto de intervención, desde una perspectiva espacio-temporal: en el escenario pasado, en el presente, en el tendencial, en el futuro y en el posible, que sirvan como base para la intervención desde el consenso social y comunitario del centro histórico de la ciudad (figuras 10 y 11 ).

Este proceso de diseño participativo es un acicate al desafío al que tienen que hacer frente las sociedades urbanas de hoy, que no puede seguir apoyándose solo en especialistas, sino que deben basarse en una colaboración interdisciplinar y participativa, donde el diseño se oriente a nutrir las necesidades espaciales y colectivas de los usuarios. 
Figura 10. Ciudadanos elaboran diagnóstico participativo del espacio público

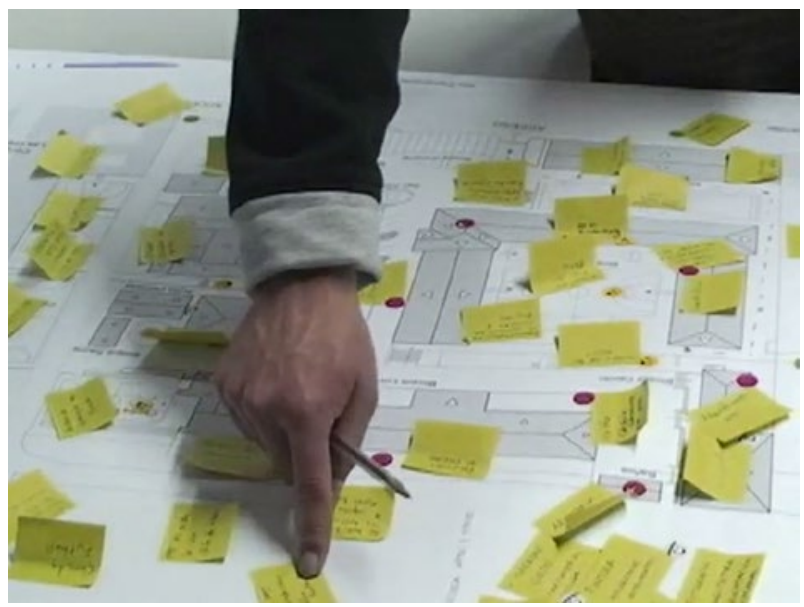

Fuente: elaboración propia

Figura 11. Talleres de diseño participativo por escenarios

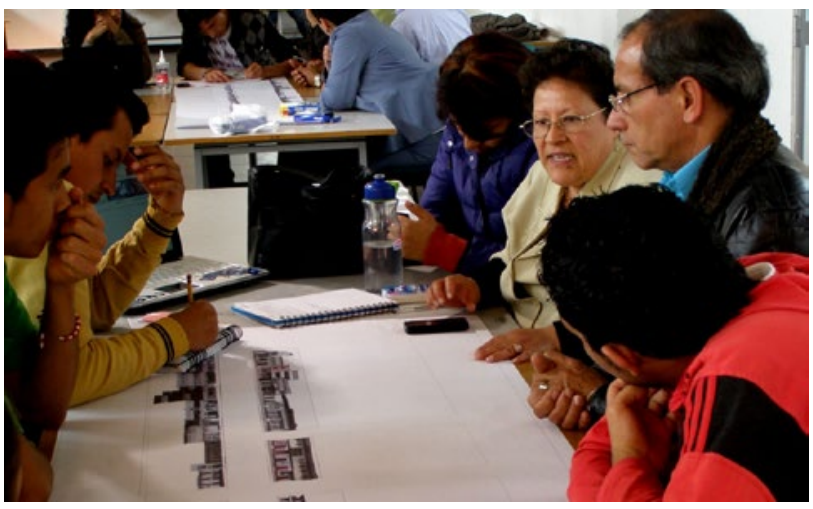

Fuente: elaboración propia.

Nota; En los TDPE, los ciudadanos de Pamplona elaboraron dibujos, narraciones escritas, compartieron experiencias y recuerdos, vivieron momentos juntos, expusieron sus ideas en público, hicieron listados, requerimientos, proyectaron sueños y programas, hicieron diagnósticos, observaciones, asistieron a charlas, conferencias, exposiciones, todas relacionadas con el tema del diseño de espacio público en el centro histórico y la ciudad de Pamplona.

\section{territarias 33}

\section{Gestión de información mediante matrices}

En el proceso de elección y de configuración de las hipótesis de diseño, el colectivo estudia, analiza, compara, evalúa y pondera los pro y los contra, las ventajas y desventajas de cada opción o alternativa, y su decisión es tanto más acertada cuantos más hayan sido los ángulos y las perspectivas bajo las cuales haya sido analizado el problema en cuestión.

En tal sentido, el proceso de marco lógico, mediante la gestión de la información con matrices, consiste, básicamente, en llevar este proceso, abordado desde múltiples ángulos de la experiencia sensorial y del conocimiento, a un mayor nivel de rigurosidad, de sistematicidad y de criticidad acorde con los alcances de toda investigación cualitativa.

El proceso de decisión no consiste en una simple lectura de datos sensoriales, sino que implica una organización activa en la que intervienen decisiones y preferencias de los colectivos participantes.

\section{El recurso de la matriz metodológica}

La matriz metodológica es de común aplicación en la investigación cualitativa, forma parte de la metodología del marco lógico y se incorpora en la presente investigación como recurso de gestión de la información condensada. Se usa para garantizar que 
se cumplan todas y cada una de las etapas previstas de exploración en el proceso de investigación y diseño participativo, lo mismo que para asegurar que las variables encontradas se articulen en coherencia horizontal y vertical, mediante la identificación de sus elementos estructurales. Con su adecuada utilización se generan aportes sustanciales y relevantes a la construcción de las ideas fuerza, directrices centrales, que habrán de guiar la toma de decisiones de diseño del espacio público.

Lo que tienen en común estas actividades es que todas ellas implican una selección entre muchas alternativas posibles. La naturaleza específica de elección tiende a legalizarse y a reflejar un conjunto de reglas institucionalizadas, por lo que es una buena manera de analizar una cultura a partir de los términos de las decisiones más frecuentemente tomadas. Es la plena legalidad de las decisiones la que convierte los paisajes en algo original, que nos permite decir si tal ciudad es italiana o, peruana, inglesa o norteamericana. Por ejemplo, ante la pregunta de por qué los medios ambientes son tan diferentes, una respuesta razonable sería la de suponer que, puesto que cada grupo cultural tiene muchas alternativas, tiende por lo tanto a escoger soluciones. Este sistema de selección o de decisión afecta también otros aspectos del comportamiento y del significado, o sea la manera a través de la cual la gente se interrelaciona, sus distancias proxémicas, la forma de estructurar el espacio, si usan o no dos calles como lugar de encuentro, etc. (Rapoport, 1978, p. 30).
En tal sentido, el diseño es considerado como un proceso de exploración de unas condiciones relacionadas con un contexto amplio, que comprende tanto el marco físico, social, económico y cultural, del ámbito de intervención, como la identificación y selección entre muchas alternativas posibles y basadas en ciertos criterios, que deberán ser explicitados y estarán asociados con unas condicionantes culturales y a la toma de unas decisiones colectivas.

El diseño del espacio urbano, es un procedimiento que permite proyectar o diseñar una realidad espacial inexistente y su resultado, producto de la aplicación de un conjunto de reglas propias de las concepciones disciplinares y, además, es expresión de lo que los grupos culturales y comunitarios identifican como de calidad urbana donde reflejan sus expectativas sociales e identidades culturales.

El diseño participativo, como proceso justificativo en busca de legitimación social, puede ser considerado como un intento de dar expresión a la imagen de un espacio público ideal y de hacer congruente ese medio ambiente ideal con uno posible, el proyectado finalmente; como respuesta coherente al espacio real. En tal sentido, se trata de un proyecto cuyos objetivos persiguen definir una nueva identidad del espacio público en el centro histórico.

\section{Mecanismo de consulta participativa}

En diferentes instancias del proceso, y conforme al avance de los talleres de diseño territarias 33

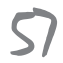


Figuras 12. Exposición de propuesta (maqueta) de diseño del Parque Águeda, en el espacio público de Pamplona

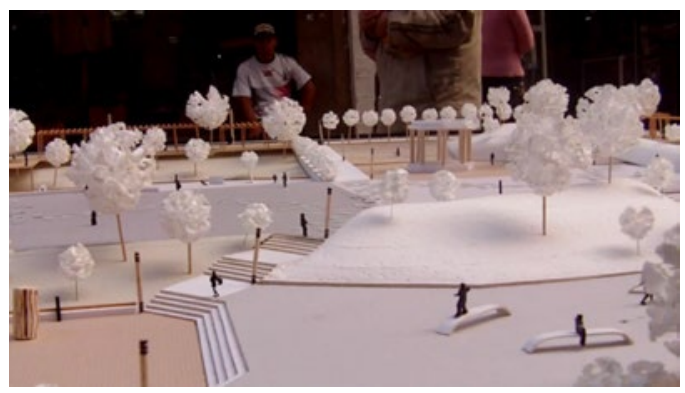

Fuente: Elaboración propia

Figuras 13. Socialización de propuesta de diseño de espacio público en la Calle Real de Pamplona

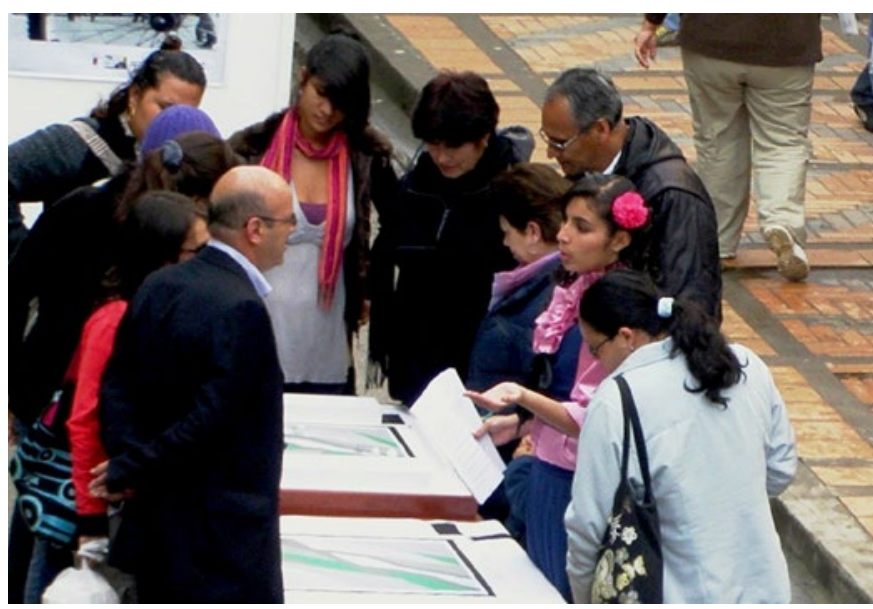

Fuente: elaboración propia.

Nota: Exposición en la Calle Real de Pamplona ( $4 .^{\circ}$ Calleralazo) de anteproyectos (maquetas, planos, imágenes 3D) de diseños de espacio público (Parque Águeda Gallardo y Calle de la U), desarrollados por arquitectos en formación, basados en las hipótesis de diseño e ideas fuerza construidas colectivamente en los TDPE. Un ejercicio de consulta y evaluación ciudadana que permite verificar si los anteproyectos propuestas, consultan o no, los requerimientos y anhelos de la comunidad, en la búsqueda de un diseño del espacio público participativo e inscrito en el contexto del centro histórico de Pamplona.

\section{territarias 33}

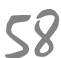

participativo y el proyecto, los arquitectos en formación muestran a la comunidad anteproyectos elaborados: enseñan planimetrías, maquetas y la infografía general para el fácil entendimiento de lo proyectado, se conversa con los usuarios sobre el porqué de cada decisión de diseño tomada y se realizan preguntas y observaciones con respecto a lo presentado. Se busca presentar diversas alternativas de diseño y hacer jornadas de socialización y negociación para ajustar el anteproyecto a los requerimientos comunitarios alcanzados en los talleres de diseño participativo por escenarios. Son jornadas cívicas y culturales, realizadas en el mismo espacio público, donde las nuevas propuestas de diseño son expuestas al público, explicadas y socializadas con el fin de verificar si estas consultaron lo que la comunidad demandó. ¿¿Recogen estos realmente el sentir de la colectividad? (figuras 12 y 13).

\section{A manera de conclusión}

El enriquecimiento del cuerpo teórico, mediante una nueva práctica pedagógica de diseño participativo, no es el fin único de la investigación, pues esto solo tiene sentido en la medida en que contribuya con la construcción de una práctica ciudadana, participativa, democrática y emancipadora para la promoción social y la creación de ciudades sustentables.

La superposición de acciones, memorias, formas y espacios, como vivencias acumuladas en el espacio urbano, permiten dibujar un mapa patrimonial del centro his- 
tórico, que se evidencia mediante talleres de participación ciudadana, métodos de consulta, de cartografía y documentación, con los cuales se construyen narrativas urbanas, se invocan memorias colectivas, se expresan ideas e iniciativas - material de valoración, imprescindible para las intervenciones y proyectos aplicables al diseño de espacio público-.

El activismo urbano, fundamentado en la memoria urbana, y la participación ciudadana, en interacción conjunta con las prácticas e investigaciones disciplinares, se hace cada vez más necesario para vencer prácticas reduccionistas, disciplinares e inconsultas, logrando la implicación generalizada de las colectividades, en procesos de construcción de ciudad, condición esencial para transitar hacia la sostenibilidad del territorio.

$\mathrm{Al}$ establecer sistemas de información interpersonal y de autoconocimiento, alrededor de los problemas de estudio e intervención, los colectivos refuerzan los sistemas de integración y participación. $\mathrm{Al}$ comprender mejor la naturaleza de los problemas espaciales y culturales con él asociados, y al abordarlos colectivamente, se generan acciones y temas que son objeto de la reflexión colectiva, aproximando la investigación a la acción, ya que el conocimiento y la reflexión se disponen para la toma de decisiones prácticas de intervención sobre el entorno.

Es esencial que las experiencias de participación ciudadana, en adelante, se realicen dentro del marco de esta metodología propuesta, sean sometidas a evaluaciones sistemáticas, con el fin de rectificar posibles errores de forma, de actuación o de fondo presentados y que no respondan a los objetivos y procedimientos establecidos. Igualmente, acopiar información de conocimientos nuevos sobre las formas, políticas e intencionalidades, que surjan de los procesos de intervención de espacios públicos o que se sustenten, principalmente, en la capacidad organizativa de los colectivos ciudadanos, dentro de un proceso de mejoramiento continuo y de acopio de mejores prácticas de participación ciudadana.

Una de las conclusiones de los talleres de diseño participativo consiste en alcanzar los indicadores cualitativos y cuantitativos que permiten identificar los aportes de los grupos involucrados y los alcances de las propuestas desarrolladas. Lo que da a los grupos la posibilidad de construir cultura de participación y la adquisición de experiencias que los harán mayormente autosuficientes. Alcanzar mayor satisfacción social en las comunidades y una valoración de las actividades de los arquitectos haciendo esta profesión útil y creativa al servicio de las comunidades.

Un alcance valioso del taller es mirar cómo se prioriza la problematización y la reflexión sobre la memoria colectiva, la conformación y estado actual del centro histórico de la ciudad para su transformación y diseño, en función de consolidar una ciudad histórica, incluyente y participativa que valora su entorno y se compromete con el bienestar social y la equidad. El mayor reto de este proyecto consistió en crear territarias 33

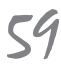


soluciones arquitectónicas satisfactorias, en la intervención del espacio público en el centro histórico de Pamplona como un logro de la cultura local, desde la dinamización social, la participación ciudadana y la creación colectiva.

La propuesta que surge es promover la formación de profesionales arquitectos y diseñadores comprometidos con la comunidad. Desarrollar ejercicios académicos con origen en la propia realidad urbana, lo que en instancias pedagógicas se denomina, aprendizaje basado en problemas. $\mathrm{El} \mathrm{\textrm {CO } ^ { - }}$ nocimiento se obtiene mediante una praxis orientada a solucionar problemas de diseño urbano de colectivos, lo que demanda un compromiso social y un proceso de participación. Los profesionales asumen el papel de asesores técnicos puestos al servicio de la comunidad, comprometidos con el análisis y el desarrollo proyectual que surge de los planteamientos y soluciones que, en consenso, proponen los mismos participantes.

La formación profesional de arquitectos, conforme a prácticas tradicionales, es una ficción que languidece y se agota en sus propias acciones simuladas, aparentemente coherentes e infalibles. Esta falacia disciplinar y reduccionista, que persiste anquilosada en las academias, se impone, dificulta la mirada compleja de la realidad, lo que este taller de investigación formativa busca explorar. Es necesario asumir el diseño del espacio desde la complejidad, pues solo mediante alianzas disciplinares y abiertas a la obligada reconversión enriquecida de la profesión seremos capaces de proponer nuevas soluciones a los proble- mas de espacio público y de ciudad, retos esenciales de este siglo XXI.

El ejercicio de la arquitectura y del diseño como se conoce está en crisis, de continuar por esta senda, más pronto que tarde, asistiremos al fallecimiento de la profesión. Es necesario salir de los encasillamientos clásicos que ubican el ejercicio de esta profesión cómo liberal y arribista. El medio para un iluso ascenso social efectivo, de genios o demiurgos solitarios, al servicio de élites políticas o de sectores económicos exclusivos. Ante este impávido panorama, ejercicios pedagógicos como este taller de diseño participativo, son indispensables.

Exigir a los responsables políticos prescindir del diseño urbano del espacio público que se impone de arriba a abajo, afín a los intereses de los políticos o del culto no cuestionado al arquitecto estrella o al proyecto ganador del concurso, ya que además de ineficiente, genera resultados controversiales debido a la exclusión, en la toma de decisiones, de los ciudadanos directamente afectados e implicados. Asumir procesos de diseño que se construyan de abajo hacia arriba y viceversa, procesos en los que ciudadanía se implique en la definición de las características programáticas y espaciales de las intervenciones a realizar.

\section{Referencias}

Borja, J. (2010). La Ciudad Conquistada. Madrid: Alianza Editorial.

Fals Borda, O. (1998). Participación Popular. Retos del Futuro. Bogotá: Tercer Mundo Editores.

Huber Giraldo Giraldo 
Halbwachs, M. (2004). La memoria colectiva. Zaragoza: Prensas Universitarias de Zaragoza.

Lefebvre, H. (1969). El derecho a la ciudad. Barcelona: Ediciones 62.
Lynch, K. (1975). ¿De qué tiempo es este lugar? Barcelona: Gustavo Gili, S.A.

Rapoport, A. (1978). Aspectos humanos de la forma urbana. Barcelona: Gustavo Gili, S.A. 